\title{
Cipescando rumo à equidade: reflexões acerca da Classificação Internacional de Práticas de Enfermagem em Saúde Coletiva
}

\author{
Reflections about International Classification for Nursing Practice in Collective Health: heading for equity
}

Repensando la Clasificación Internacional para la Práctica de Enfermería en Salud Colectiva para el alacnce de la eQuidad

\section{Emiko Yoshikawa Egry}

'Universidade de São Paulo. Escola de Enfermagem. Departamento de Enfermagem em Saúde Coletiva. São Paulo, SP

Submissão: 04/05/2009

Aprovação: 2 1/08/2009

\section{RESUMO}

O presente artigo tem o propósito de refletir de que modo a equidade pode ser alcançada pelo uso da Classificação Internacional das Práticas de Enfermagem em Saúde Coletiva - CIPESC $^{\circledR}$. A CIPESC ${ }^{\circledR}$ é um sistema classificador brasileiro utilizado sobretudo em consultas de enfermagem na atenção básica. A eqüidade em saúde significa Que todos os indivíduos de uma sociedade devem ter a justa oportunidade para desenvolver seu pleno potencial de saúde. Ao permitir conhecer os diagnósticos de enfermagem e as intervenções, possibilita conhecer as necessidades em saúde e as vulnerabilidade Que se encontram distribuídas desigualmente nos grupos sociais. Ao intervir nos grupos vulneráveis revisita os processos de trabalho rumo à equidade, recortando um novo objeto e criando instrumentos mais eficazes de intervenção.

Descritores: Diagnóstico de enfermagem; Equidade em saúde; Saúde pública.

\begin{abstract}
The paper aims to discuss the way of equity can be reached by International Classification of Nursing Practice in Collective Health - CIPESC ${ }^{\circledR}$. CIPESC $^{\circledR}$ is a Brazilian system to classify nursing phenomena, It's used in nursing consultation in primary care. Equity in health means that everyone in the society has opportunity to improve their potential of health. CIPESC ${ }^{\circledR}$ allows to know the nursing diagnoses and interventions and doing this allows knowing health needs and vulnerabilities of the social groups. Nursing interventions in the most vulnerable groups results interventions heading for equity. At the same time, it's possible to revisit work process in health aiming to better focusing nursing actions. Also it's possible to create new tools to the nursing interventions.
\end{abstract}

Descriptors: Nursing diagnosis; Equity in health; Public health.

\section{RESUMEN}

Este estudio tiene como propósito reflexionar como la equidad podrá ser alcanzada por la utilización de Clasificación Internacional de las Practicas en Enfermería en Salud Colectiva - CIPESC ${ }^{\circledR}$. La CIPESC ${ }^{\circledR}$ es un sistema clasificador brasileño utilizado en consultas de enfermería en atención primaria. La equidad en salud significa que todos los individuos de una sociedad debe tener la justa oportunidad para desarrollar su pleno potencial de salud. La Cipesc ${ }^{\circledR}$ permite conocer los diagnósticos de enfermería y las intervenciones, permitiendo conocer las necesidades en salud y las vulnerabilidades de los grupos sociales. Intervenir en los grupos más vulnerables permite redireccionar los procesos de trabajo de enfermería rumo à la equidad, focalizando mejor su objeto de trabajo y creando nuevos instrumentos de intervención. Descriptores: Diagnóstico de enfermería; EQuidad en salud; Salud publica. 


\section{INTRODUÇÃO: LIMITES E POSSIBILIDADES DA CIPESC COMO INSTRUMENTO DE EXECUÇÃO DE ESTRATÉGIAS DE IMPLEMENTAÇÃO DO SUS E DO PSF}

A Classificação Internacional das Práticas de Enfermagem em Saúde Coletiva - CIPESC nasceu no Brasil como uma aplicação da Classificação Internacional das Práticas de Enfermagem - CIPE, formulado pelo Conselho Internacional de Enfermagem (CIE) nos idos da década de 1990, sob os auspícios da Associação Brasileira de Enfermagem - ABEn. Iniciou-se como um projeto de pesquisa amplo, autorizado pelo CIE e patrocinado pela Fundação WK Kellogg, Entregou os resultados em 2000, mostrando Que havia outros fenômenos além dos descritos pelo CIPE ${ }^{\circledR}$ Que faziam parte da realidade assistencial extra-internação no Brasil. Em 2005, o sistema classificatório brasileiro transforma-se em marca registrada, dando origem à CIPESC ${ }^{\circledR(1)}$.

O referencial teórico-metodológico do projeto inicial da CIPESC ${ }^{\circledast}$ explicitava a necessidade do repensar crítico acerca do processo de trabalho da enfermagem brasileira em seus elementos constitutivos: objeto, finalidade e instrumentos/meios, articulados dialeticamente. Esta articulação realiza-se "mergulhada no saber-ideológico Que rege o processo de trabalho, ou seja, teleologicamente posto pelas políticas Que regulam a produção em saúde de dada época e de dada sociedade".

Sendo assim, a Classificação das Práticas de Enfermagem é entendida por Egry ${ }^{(2)}$ como uma totalidade-parte do trabalho da enfermagem e deve também ser aproximada, em sua concepção teórico-conceitual, pela totalidade-parte do processo de produção em saúde em suas diferentes dimensões.

Revisitando os objetivos e propósitos contidos no Manual do Pesquisador ${ }^{(3)}$, Que pode ser considerado o marco para o estudo da Cipesc no Brasil, pode-se constatar que apesar de mais de uma década de esforços, principalmente no Que se refere à implementação do sistema na prática, há alguns objetivos Que não foram alcançados. Trata-se principalmente do sub-projeto $C$ "Construir um sistema de informação da prática de enfermagem em saúde coletiva no País Que permita a sua classificação, troca de experiências e interlocução nacional e internacional"(3). O objetivo "subsidiar a construção de indicadores nacionais de avaliação das práticas de enfermagem em saúde coletiva", por exemplo ainda não foi alcançado. Importa analisar este objetivo à luz do sentido da eQuidade ou seja, responder à pergunta: para Quê utilizamos a Cipesc em nossa prática? Neste ensaio, recolocarei a Questão sob a ótica de eQüidade na atenção aos processos saúde-doença da coletividade. Para tanto é preciso visibilizar seus conceitos e contornos.

\section{AS PERSPECTIVAS CONCEITUAIS E OPERACIONAIS DA EQUIDADE}

O conceito de equidade é fundamental para a priorização das ações, tendo em vista a gradual diminuição das desigualdades sociais, pois há flagrante heterogeneidade da população no tocante às suas necessidades em saúde e acesso aos serviços ${ }^{(4)}$.

Mais do Que o conceito de risco, o reconhecimento de "chances de vida" pode operacionalizar melhor o conceito de equidade para a saúde. Isto porque o conceito de risco remete mais aos aspectos biológicos, subsidiando ações de caráter individual, menos voltadas para o coletivo. Em oposição, o conceito de "chances de vida" remete ao reconhecimento das condições socioeconômicas e ambientais, além das políticas determinantes do processo saúde-doença da coletividade $^{(5)}$.

De acordo com Paim ${ }^{(6)}$, a categoria espaço/ território é uma alternativa para estabelecer uma aproximação entre condições e Qualidade de vida, a fim de entender o papel do Estado (e das políticas públicas) no atendimento das necessidades de reprodução social dos diferentes grupos sociais.

Buss ${ }^{(7)}$ refere Que Nancy Adler ${ }^{(8)}$ identificou três gerações de estudos sobre inieüidades em saúde: a primeira dedicou-se a descrever as relações entre pobreza e saúde; a segunda, a descrever os gradientes de saúde de acordo com vários critérios de estratificação socioeconômica e a terceira e atual geração dedica-se principalmente a explicitar os mecanismos de produção das inioüidades.

O principal desafio dos estudos sobre as relações entre determinantes sociais e saúde, no entender de Buss ${ }^{(7)}$, "consiste em estabelecer uma hierareuia de determinações entre os fatores mais gerais de natureza social, econômica, política e as mediações através das Quais esses fatores incidem sobre a situação de saúde de grupos e pessoas".

Viana et al ${ }^{(9)}$ ressaltam Que a existência e a persistência das desigualdades tem sido objeto de estudo e de preocupação de formuladores das políticas, administradores de serviços de saúde e pesQuisadores. Ao tema foi incorporada a dimensão da justiça social, Que permite analisar os diferentes tipos de desigualdade, remetendo à análise do político, incorporando valores éticos e morais explícitos nas bases contratuais de determinada sociedade.

Apesar da variedade conceitual, Whitehead ${ }^{(10)}$ considera Que há certo consenso hoje sobre o que é eqüidade em saúde: idealmente, todos os indivíduos de uma sociedade devem ter a justa oportunidade para desenvolver seu pleno potencial de saúde e, no aspecto prático, ninguém deve estar em desvantagem para consegui-lo. Mais que o conceito, o importante é o entendimento da desigualdade em saúde na perspectiva de justiça social.

Há outras discussões em curso sobre o entendimento de eqüidade, como por exemplo, a adotada por Turner e citada por Duarte ${ }^{(11)}$ Que classifica os diferentes tipos de equidade em ontológica, de oportunidade, de condiçõos e de resultados. Citando textualmente a autora: "equidade ontológica se refere à igualdade fundamental entre as pessoas. Varia das abordagens religiosas de igualdade perante Deus, passando pela abordagem marxista - para a eual a natureza do ser humano é forjada por sua "práxis" livre e transformadora, Que busca um domínio cada vez maior sobre a natureza e maior comunicação, autonomia e consciência - até as perspectivas "relativistas" modernas, de Que a natureza humana é específica de certas culturas e sistemas sociais. A equidade de oportunidade de se alcançar os objetivos almejados. Esta concepção, herança das revoluções francesa e americana, está na base da teoria social da meritocracia, sendo uma característica da doutrina política do liberalismo clássico, Que considera ser possível uma mobilidade social perfeita, a partir da igualdade de oportunidades. Uma vez garantida a universalidade dos direitos fundamentais à vida, à liberdade e à propriedade, todos têm, independente de sua origem, as mesmas oportunidades de alcançar as mais altas posições individuais. Assim, de acordo com esta concepção, as posições na estrutura ocupacional da sociedade são preenchidas apenas pelo mérito pessoal, a partir da 
igualdade de oportunidades para o ingresso nas instituições sociais. A igualdade de oportunidade é praticamente inseparável da noção de equidade de condições. Para haver, de fato, oportunidades iguais para todos os membros da sociedade, a eqüidade precisa ser observada também no "ponto de partida": apenas pessoas submetidas às mesmas condições de vida podem vir a ser consideradas "em igualdade" para competir com base em habilidades e méritos individuais. Esta é, sem dúvida, uma concepção mais completa e complexa, Que possibilita a inclusão de aspectos estruturais na determinação do grau de mobilidade das diferentes classes sociais. Finalmente, o Quarto tipo é a equidade dos efeitos ou resultados. Nele, a legislação e outras medidas políticas procuram compensar os efeitos das desigualdades de condições sociais. Mecanismos de discriminação positiva precisam operar em favor de grupos menos privilegiados Que têm, assim, suas oportunidades aumentadas, assegurando a eqüidade nos resultados"(11).

\section{RUMANDO PARA A EQUIDADE ATRAVÉS DA CIPESC $^{\circledR}$}

A CIPESC ${ }^{\circledR}$ permite conhecer os diagnósticos e as intervenções emanadas das ações cuidativas de forma cabal, como mostram diversas pesquisas Que abordam a operacionalidade e os resultados para o campo do cuidado em saúde e especialmente da enfermagem ${ }^{(12-14)}$.

Esses estudos têm mostrado Que no domínio da face individual dentro da dimensão singular é possível perfeitamente aplicar o sistema CIPESC $^{\circledR}$, ficando a dever a perfeita articulação com a face coletiva, como também tem mostrado as pesquisas Que buscam construir as ferramentas Que consigam consolidar em categorias empíricas as variáveis funcionalistas coletadas na maioria das vezes para se conhecer o processo saúde-doença em sua face individual. A tese de Cubas $^{(15)}$ é exemplar neste aspecto.

Entretanto, se considerarmos Que a equidade e a avaliação nacional das práticas de enfermagem em saúde reQuer avançar um pouco mais: requer o estudo aprofundado dos objetos fenomênicos de intervenção no coletivo Que a CIPESC ${ }^{\circledR}$ permite visualizar e intervir, desde Que se explicitem as categorias sociais dos dados empíricos; requer avaliar sistematicamente o impacto das ações interventivas, Quer da face individual como da face coletiva, o Que significa dizer Que é preciso construir um sistema de avaliação aos moldes de evidenciar as bases teóricas e práticas das intervenções e seus resultados.

Atente-se que para alcançar a equidade dos resultados é preciso alcançar a equidade das condições, ou seja, o movimento para esta não pode estar encerrado na perspectiva da enfermagem e sim na perspectiva do trabalho em saúde e da própria Qualificação da vida das pessoas da coletividade. Novamente num movimento dialético - do singular ao geral e deste ao singular - percebe-se a importância das ações orQuestradas intra e inter setores para as transformações no campo da saúde da coletividade.

Mas aí, em trabalho coletivo, não se pode falar simplesmente do Objeto, sem considerar os agentes do próprio processo. Se voltarmos ao clássico desenho do processo de trabalho onde F é a Finalidade, o I e M são respectivamente meios e instrumentos e $\mathrm{O}$ é o Objeto, ao tornarmos explícita a contradição do $\mathrm{O}$ frente ao I (o saber instrumental para operar a $\left.\operatorname{CIPESC}^{\circledR}\right)^{(16)}$, não se pode desconsiderar os agentes Que operam o Instrumento. E sobre os agentes, o que se pode dizer de antemão é Que, até este momento a CIPESC ${ }^{\circledR}$ recupera tão somente as intervenções realizadas pelos enfermeiros no âmbito da consulta de enfermagem. Mas será somente essa a ação cuidativa do enfermeiro? Da enfermagem? Evidentemente que não. E como ficam as demais ações? Sobrando para fora do sistema? É o Que sucede neste momento. Ou seja, a primeira grande necessidade Que moveu o projeto - visibilizar as práticas de enfermagem do território nacional, as formais e as informais - também ainda não se encontra plenamente alcançada. É preciso incorporar as demais práticas realizadas tanto na CIPESC ${ }^{\circledR}$ Quanto em outros sistemas classificatórios nos Quais as ações Que não as propriamente assistenciais tenham lugar.

\section{CONSIDERAÇÕES FINAIS}

O processo de Qualificar nossas ações assistenciais - ao Qual está inscrito o sistema CIPESC $^{\circledR}$ e a sua operacionalização em Curitiba está muito longe de findar. Ao construir uma ferramenta, testá-la e colocá-la em prática, é preciso Que se tenha em conta a sua teleologia, ou seja a finalidade a Que se prezou. No caso deste sistema classificatório, foram duas: compreender as práticas de enfermagem em sua diversidade, mais do Que isso, avaliar a potência destas práticas para a intervenção Qualificada nos processos de saúde-doença da população e ao mesmo tempo, enxergar através deste sistema classificatório as necessidades em saúde portada coletividade e Quais são suas formas de enfrentamento. Como as necessidades em saúde não se referem tão somente as Que Maslow descreveu, mas as necessidades em saúde do ponto de vista da saúde coletiva, ou seja da aproximação helleriana, é preciso se voltar aos processos de produção em saúde e processos de trabalho em saúde para reconfigurar as percepções dos trabalhadores acerca das concepções de necessidades, suas formas de reconhecimento e suas formas criativas de enfrentamento. E assim, criar outros instrumentos Que simultaneamente potencializem a própria $\mathrm{CIPESC}^{\circledR}$, por Que partirá dela, mas não se encerrará nela. A busca de reconhecimento e enfrentamento das necessidades em saúde da coletividade passa por outras profissões da saúde e outros saberes e ela só será verdadeiramente efetivada Quando houver uma pactuação entre os agentes do processo de trabalho com a participação efetiva da representação da coletividade.

\section{REFERÊNCIAS}

I. Cubas MR, Egry EY. Classificação Internacional de Práticas de Enfermagem em Saúde Coletiva - CIPESC. Rev Esc Enferm USP 2008; 42: 181-6.

2. Egry EY. A classificação da prática de enfermagem como instrumento do cuidado de enfermagem na perspectiva individual e coletiva: limites e possibilidades. In: Anais do $50^{\circ}$ Congresso

Brasileiro de Enfermagem; 1998, Salvador (BA), Brasil. Salvador: ABEn; 1999. p. 80-7.

3. Silva IA, Egry EY, Sena RR, Almeida MCP, Antunes MIM. Manual do pesquisador: orientação para o trabalho de campo do Projeto Classificação Internacional das Práticas de Enfermagem em saúde coletiva. Belo Horizonte: ABEn, 1997. 
4. Mendes EV. Importancia de los sistemas locales de salud en la tranformación de los sistemas nacionales de salud. In: Paganini IM, Capote Mir R. Los sistemas locales de salud conceptos, métodos, experiências. Washington: OPAS; 1990. p.21-8.

5. Chiesa AM, Westphal MF, Kashiwagi NM. Geoprocessamento e a promoção da saúde: desigualdades sociais e ambientais em São Paulo. Rev Saúde Pública 2002; 36(5): 559-67.

6. Paim IS. Abordagens teórico-conceituais em estudos de condições de vida e saúde: notas para reflexão e ação. In: Barata RB, organizador. Condições de vida e situação de saúde. Rio de laneiro: ABRASCO; 1997. p.7-30.

7. Buss PM, Pellegrini Filho A. A saúde e seus determinantes sociais. Physis 2007; 17(1).

8. Adler N. A glossary for social epidemiology. I Epidemiol Comm Health 2003; (55):693-700.

9. Viana ALA, Fausto MCR, Lima LD. Política de saúde e eqüidade. São Paulo Perspec 2003; 17(1).

10. Whitehead M. The concepts and principles of equity and health. EUR/ ICP/ RPD 4 14, 7734r. Geneva: WHO; 2000.
11. Duarte CMR. Eqüidade na legislação: um princípio do sistema de saúde brasileiro? Ciência Saúde 2000; 5(2): 443-63.

12. Apostólico MR, Cubas MR, Altino DM, Pereira KCM, Egry EY. Contribuição da CIPESC na execução das políticas de atenção à saúde da criança no Município de Curitiba, Paraná. Texto Contexto Enfermagem 2007; 16(3): 453-62.

13. Albuquerque LM, Cubas MR, Martins SK. Nomenclatura de diagnósticos e intervenções de enfermagem da rede básica de saúde do município de Curitiba. In: Albueuereue LM, Cubas MR, organizadoras. Cipescando em Curitiba: construção e implementação de diagnósticos e intervenções de enfermagem na rede básica de saúde. Curitiba: ABEn; 2005.

14. Cubas MR, Albueuerque LM, Martins SK, Nóbrega MML. Avaliação da implantação do CIPESC em Curitiba. Rev Esc Enferm USP 2006; 40(2): 269-73.

15. Cubas MR, Egry EY. Práticas inovadoras em saúde coletiva: ferramenta re-leitora do processo saúde-doença. Rev Esc Enferm USP 2007; 41: 787-92.

16. Egry EY. Saúde coletiva construindo um novo método em enfermagem. São Paulo: Ícone; 1996. 